\title{
A CLINICO-INVESTIGATIVE STUDY OF ALOPECIA AREATA WITH SPECIAL REFERENCE TO ITS ASSOCIATION WITH VARIOUS SYSTEMIC AND DERMATOLOGICAL DISORDERS.
}

Gopal M.G1, Praveen Kumar S², Sharath Kumar B.C ${ }^{3}$, Ramesh M $^{4}$

\section{HOW TO CITE THIS ARTICLE:}

Gopal MG, Praveen Kumar S, Sharath Kumar BC, Ramesh M. "A clinico-investigative study of alopecia areata with special reference to its association with various systemic and dermatological disorders". Journal of Evolution of Medical and Dental Sciences 2013; Vol2, Issue 48, December 02; Page: 9239-9249.

ABSTRACT: BACKGROUND: Alopecia areata is believed to be an autoimmune condition with a worldwide occurrence. It usually presents as patchy, non-scarring hair loss. There is a paucity of clinical data in Asians. OBJECTIVES: To describe the demographic profile, clinical profile and histopathology of alopecia areata $d$ out the association with various systemic and dermatological disorders. METHODS: 120 cases were included for the study, over a period of 18 months from January 2007 to June 2008. A descriptive study with purposive sampling was done. Demographic data and a detailed history of the patient to rule out associated systemic and dermatological disorders and various autoimmune disorders were documented. RESULTS: 45 (37.5\%) out of 120 cases were in the age group of 21-30 years. Male:Female ratio was 2:1. 103 (85.8\%) patients were Hindus from urban background who were skilled workers. Parietal area was the commonest area involved over scalp, in $38(31.67 \%)$ patients. All these data are statistically significant. 7 (5.8\%) patients had seborrhoeic dermatitis of scalp, $2(1.6 \%)$ patients had lichen planus and Vitiligo. $1(0.8 \%)$ patient had psoriasis. Family history of alopecia areata was noted in $8(6.7 \%)$ patients. Pitting was noted in $14(11.7 \%)$ patients. 41 (93.2\%) patients in urban background had emotional stress.

KEY WORDS: Alopecia areata, Autoimmunity, systemic disorders

INTRODUCTION: Alopecia areata is characterized by the loss of hair in circumscribed patches. The patches may be later being round or oval or irregular in shape, of varying size and accompanied by little or no evidence of inflammation. Alopecia areata is a multifactorial disease with autoimmune components, which although seen in genetically predisposed individuals, the real causes have yet to be determined and various factors should be considered. A variety of environmental factors including infections, drugs, trauma, and stress have been suggested as triggering factors for alopecia areata, although most patients of alopecia areata are unaware of any obvious precipitating factors, it is possible though hard to prove, that a diversity of insults, physical or psychological, may trigger episodes of alopecia areata but there is no influence that they affect prognosis. There are reported associations between alopecia areata and classic auto-immune disorders. The main ones being thyroid disorders and vitiligo. The presence of peribulbar lymphocytic inflammatory infiltrate is a histopathologic characteristic found in most of the terminal hair in one evolutionary stage: catagen or telogen. The follicles become smaller during the course, forming miniaturized hair and are substituted by fibrous tracts.

MATERIALS AND METHODS: This study approved by the ethical committee was conducted in Kempegowda Institute of Medical Sciences for a period of one and a half years between January 2007 to June 2008. After obtaining clearance and approval; from the institutional ethical committee, 


\section{ORIGINAL ARTICLE}

120 consecutive cases were included for the study. After obtaining the written consent, the study subjects were subjected to detailed history taking including demographic data, drug history, personal history, family history, present and past medical history and history of emotional stress exposure to STD and drug intake. A detailed history of the patient to rule out associated systemic and dermatological disorders and various autoimmune disorders were made. The available records were scrutinized to collect any valid data. A thorough clinical evaluation was done: to assess the clinical pattern, extent severity and duration of alopecia areata, to detect any predisposing or any underlying disease/pathological factors, to assess any other organ system involvement and assess the presence of other dermatological disorders as suggested by detailed history were done. Nail changes were documented in all patients. Histopathology of alopecia areata were studied in selected.

Inclusion criteria: All diagnosed and suspected cases of alopecia areata visiting or referred to Department of Dermatology, Kempegowda Institute of Medical Sciences and Research Centre, Bangalore.

Exclusion Criterion: Patients not willing to give written or informed consent and not willing to participate in the study and various types of alopecias, other than alopecia areata.

Statistical methods: The data was analyzed statistically using descriptive statistics namely Mean, Proportion and Standard Deviation and Chi Square test. Wherever necessary the results are depicted in the form of graphs of percentages.

RESULTS: The age-wise distribution of alopecia areata is shown in [table 1]. 45 (37.5\%) out of 120 cases were in the age group of 21-30 years. 28 (23.3\%) were in the age group of 31-40 years. 80 $(66.7 \%)$ patients were males and $40(33.3 \%)$ were females. Male:Female ratio as 2:1,as shown in [table 2]. 103 (85.8\%) patients were Hindus [table 3]. 87 (72.5\%) patients were from urban background [table 4]. 42 (35\%) patients were in income range >Rs.3375-6749.40 [table 5]. (33.3\%) patients had the educational status, degree and above [table 6]. 37 (30.83\%) patients were skilled workers [table 7]. Parietal area was the commonest area involved over scalp, in 38 (31.67\%) patients [table 8], frontal area was the second with 23(19.17\%) patients being involved. All these data are statistically significant. Beard was the commonest area involved over face, in 15 (12.5\%) patients [table 9]. [table 10] shows associated dermatological disorders. 7 (5.8\%) patients had seborrhoeic dermatitis of scalp, 2 (1.6\%) patients had lichen planus and Vitiligo. 1 (0.8\%) patient had psoriasis. [Table 11] depicts associated systemic disorders. Diabetes mellitus being the commonest with 7(5.8\%) patients. The next commonest ones being bronchial asthma and anemia in $5(4.2 \%)$ patients respectively. [Table 12] depicts associated dermatological and systemic disorders in family members. Family history of alopecia areata was noted in $8(6.7 \%)$ patients. Family history of bronchial asthma was noted in $3(2.5 \%)$ patients. Family history of Vitiligo were noted in 2 (1.7\%) patients. Family history of diabetes was seen in $4(3.3 \%)$ patients. Pitting was commonest nail change noted in $14(11.7 \%)$ patients [Table 13]. 41 (93.2\%) patients in urban background had emotional stress [Table 14]. 25 patients in income group Rs. 6750 to 13,499 had emotional stress [Table 15]. 


\section{ORIGINAL ARTICLE}

DISCUSSION: Alopecia areata is a common, unpredictable, non-scarring form of hair loss ${ }^{1}$. Although alopecia areata can occur at any ages from infancy to old age ${ }^{2}$, the first attack is most commonly seen between the age of 5 and 40 years and accounts for 70 to $80 \%$ of cases. The onset of alopecia areata may be at any age, peaking between second and fourth decades. In our study, the commonest age group of occurrence was $21-30$ years accounting to $37.5 \%$. The next common age group in our study was 31 to 40 years accounting to $23.3 \%$. This clearly indicates that, in our study the commonest age group was between 21 to 40 years, which is in line with the studies done before.

Sex incidence is reported to be equal in UK and USA, but figures from France, Italy and Spain show a considerably higher incidence in males about 2:1 of male:female ratio. Our study shows $66.7 \%$ of patients were males and 33.3\% were females (approximately the ratio being 2:1). This in line with the studies done before, and is in accordance with the studies done in south-west European countries.

The percentage of Hindus among the patients was 85.8\%, next common being Muslims at 8.3\% and Christians being 5.8\%. The majority of the patients were Hindus. $72.5 \%$ of patients were from urban background, and $27.5 \%$ were from rural background. $35 \%$ of patients were in income range $>$ Rs.3375-6749. 32.5\% of patients were in income range Rs.6750-13499. 19.2\% of patients were in income range $<$ Rs.3374. 13.3\% of patients were in income range $>$ Rs.13,500.This clearly indicates that most of the patients were in the income range Rs. 3375-6749.

The total number of patients in the group of educational status degree and above were $33.3 \%$. The total number of literate population was $20 \%$. The total number of patients in P.U.C group were $17.5 \%$. The total number of illiterate population was $11.7 \%$. The total number of patients in primary school group were $9.2 \%$. The total number of patients in high school group were $8.3 \%$. This clearly indicates that the majority of the patients are in group degree and above and next common ones are in literate group. This can be attributed to the fact educated people have more knowledge about seeking professional medical advice for their health related problems.

Most of the patients in our study were skilled workers amounting to $30.83 \%$, patients with semi-skilled occupation being $26.6 \%$, unskilled ones being $25 \%$, and not applicable ones being $17.5 \%$. This clearly indicates that alopecia areata in our study was commonly seen in skilled workers.

Alopecia areata is usually confined to one portion of the body, but not necessarily the scalp. In Muller and Winkelman's ${ }^{3}$ study $95 \%$ of the patients had scalp affection. ${ }^{19}$ The study done by Awachat AK et $\mathrm{al}^{4}$ shows that involvement of various regions of scalp were as follows [Table 16]. This indicates that the commonest area of involvement over scalp was the Parietal area. This is statistically significant and correlates with the previous study.

The percentage of beard involvement according to Awachat $\mathrm{AK}$ et al ${ }^{4}$ was $12 \%$ [Table 17]. This shows that beard was involved in $12.5 \%$ of cases and is statistically significant and is in line with the studies done before. In our study beard was the commonest area involved over the face. Eyebrows were involved in $7.5 \%$ of cases, eyelashes in $0.83 \%$ and mustache in $7.5 \%$ of cases, extremities in $5.83 \%$ and pubic hair in 1 case $0.83 \%$. Alopecia totalis was seen in 2 cases and 1 case progressed from alopecia totalis to universalis.

ASSOCIATED DERMATOLOGICAL DISORDERS: Seborrhoeic dermatitis was seen in 5.8\% of cases. Psoriasis and impetigo were seen in $1.6 \%$ cases each. The other dermatological disorders 5 associated were Lichen planus, Lichen nitidus, Hypertrophic lichen planus, Lichen planus pigmentosus, 


\section{ORIGINAL ARTICLE}

Palmoplantar keratoderma, Schambergs purpura, Steatocystoma multiplex in $(0.8 \%)$ of cases each. Totally 2 cases of Vitiligo was seen amounting to (1.6\%), of which 1 case each were associated with Psoriasis and Syringomas respectively. Muller and Winkelman studies have shown that association of alopecia areata with Vitiligo to be $4 \%$. In our study association with Vitiligo is $1.6 \%$. Lichen planus, Psoriasis and Vitiligo have a proposed autoimmune etiology. In our study, with these associations trends are available that could indicate that alopecia areata could be an autoimmune disorder. But further studies are needed in this regard.

ASSOCIATION WITH SYSTEMIC DISORDERS: Bronchial asthma was seen in $4.2 \%$ of cases. Diabetes mellitus was seen in 5.8\% cases. Hypothyroidism was seen in $2.5 \%$ cases. Down's syndrome, chronic pyelonephritis, pneumonia and varicose veins were seen in $0.8 \%$ cases each. Hypothyroidism, bronchial asthma and diabetes mellitus have a proposed autoimmune ${ }^{6}$ etiology. Muller and Winkelman ${ }^{3}$ studies showed association of alopecia areata with atopy in 18\% of children and 9\% of adults. In study by Ikeda ${ }^{1}$ percentage of association with atopy was $10 \%$. In our study, with these associations trends are available that could indicate that alopecia areata could be an autoimmune disorder. But further studies are needed in this regard.

ASSOCIATED FAMILY HISTORY: In our study, family history of alopecia areata was seen in 6.7\% cases, Bronchial asthma in $2.5 \%$ cases. This attributes to $9.2 \%$ of patients, associated with atopy. Family history of diabetes mellitus was seen in 3.3\% cases. One case had both diabetes mellitus (Type II) and hypertension (0.8\%). One case had history of psoriasis (0.8\%) cases. 2 cases had family history of vitiligo $(1.7 \%)$. In our study $14.1 \%$ cases had association with other autoimmune disorders mentioned above. In our study, with these associations trends are available that could indicate that alopecia areata could be an autoimmune disorder. But further studies are needed in this regard. There are several reports of occurrence of alopecia areata in families and occurrence of the same in twins at the same site and also the onset of time being the same. Percentage of family history ranges from 10$27 \%$ as per Dan A. Nelson et al in their study.

NAIL INVOLVEMENT IN ALOPECIA AREATA: In our study, Pitting was seen in $11.7 \%$ cases and was the commonest finding. King Muller ${ }^{3}$, and Read noted pitting in 66\%. Leukonychia was seen in 5.8\% cases. 20 nail dystrophy was seen in $0.8 \%$ of cases. In our study pitting was the commonest nail finding.

STRESS AND ALOPECIA AREATA: In Muller and Winkelman ${ }^{3}$ studies $12 \%$ patients had emotional disturbances which could be attributed to hair loss. Out of $44(100 \%)$ patients, $41(93.2 \%)$ were from urban background and they had emotional stress and $3(6.8 \%)$ patients in rural background had emotional stress. In our study, stress was more in patients from urban area than rural area. Emotional stress was seen in 25 patients were in income group Rs. 6750-Rs.13,499. 16 patients in income group $>$ Rs.13,500, 2 patients in Rs. 3375-Rs.6749/-, 1 patient in <Rs. 3374/-. These clearly indicate that patients in income group Rs.6750-Rs.13,499/- had significant stress. Stress was also more in income group Rs. 6750-13499/-. This could be attributed to the fact that people from urban area with low income have more stress than people in rural areas. This can also be attributed to the high cost of 


\section{ORIGINAL ARTICLE}

living in the urban areas. There are previous studies ${ }^{7}$ to show the correlation between stress and alopecia areata.

HISTOPATHOLOGY8,9 OF ALOPECIA AREATA: Biopsy was done in selected cases (in a total of 25 patients) and most of the cases showed features of peribulbar lymphocytic inflammatory infiltrate(Figure 1,2). In our study more number of telogen follicles were found in comparison to anagen hair follicles. Around Telogen hair inflammatory infiltrate was less than anagen hair follicles. Telogen hairs show little or no perifollicular inflammation. The number of Catagen and telogen follicles found may be marked, approaching 100\%. Follicles may enter a persistent phase of telogen in which the hair shaft has already been shed, manifested by the telogen germinal unit. Whiting and others have emphasized the use of follicular counts to aid in the diagnosis of alopecia areata when the characteristic peribulbar inflammation is missing, with a high percentage of catagen or telogen hairs and miniaturized hairs as a strong sign of alopecia areata.

TRICHOGRAM ANALYSIS: In our study, Trichogram analysis was done in 5 cases and in most of the patients more of Telogen hairs compared to anagen hairs were noted. In a 2 patients, dystrophic hairs and catagen hairs were more compared to anagen hairs. Exclamatory mark hairs ${ }^{10}$ were seen in all cases.

TREATMENT OPTIONS IN ALOPECIA AREATA: The treatment options for alopecia areata are diverse, and the treatment options are based on the age of the patient and the extent of disease. For children less than 10 years topical minoxidil, corticosteroids and in resistant cases anthralin therapy is used. In children more than 10 years, if more than $50 \%$ area of involvement, immunotherapy is used as a first line therapy. If the response in 6 months is poor, than systemic corticosteroids and PUVA therapy is tried as a second line therapy. If the response to this is poor then azathioprine, cyclosporine area used as a third line therapy. Excimer laser therapy is tried in lesions less than 50\% of scalp surface area.

CONCLUSION: In our study trends are available that indicate that alopecia areata could be autoimmune but further studies are needed in this regard. Patients had significant association with emotional stress and stress was common in the income group Rs.6750 to Rs.13, 499/-. A holistic approach is important in the management of alopecia areata as the disease can have a severe psychologic impact on an individual's well-being.

\section{REFERENCES:}

1. 1 .Ikeda T. A new classification of alopecia areata. Dermatologica 1965; 131:421-45.

2. Mitchell AJ, Krull EA. Alopecia areata: Pathogenesis and treatment. J Am Acad Dermatol.1984;11:763-75.

3. Muller HK, Winkelmam RK. Alopecia areata. Arch Dermatol 1963;88:290-97.

4. Awachat AK, Sharma ML, et al. Alopecia areata. Arch Dermatol 1960; 26: 59 - 70.

5. 5.Sharma V, Kumar B, Dawn G. A clinical study of childhood alopecia areata in Chandigarh, Indian Pediatr Dermatol 1996;13:372-7. 


\section{ORIGINAL ARTICLE}

6. Hordinsky M, Ericson M. Autoimmunity: Alpecia areata.J Investig Dermatol SympProc. 2004;9:73-8.

7. Reinhold M. Relationship of stress to the development of symptoms in alopecia areata and chronic urticaria. Br Med J 1960;1:846-9.

8. Sellheyer K, Bergfeld WF. Histopathologic evaluation of alopecias. Am J Dermatopathol. 2006;28:236-59.

9. Stefanato CM. Histopathology of alopecia: a clinicopathological approach to diagnosis. Histopathology. 2010;56:24

10. Madani S, Shapiro J. Alopecia areata update. J Am Acad Dermatol 2000;42:549- 66.

\begin{tabular}{|c|c|c|}
\hline Age (years) & Frequency & \% of patients \\
\hline$<10$ & 15 & 12.5 \\
\hline $11-20$ & 17 & 14.2 \\
\hline $21-30$ & 45 & 37.5 \\
\hline $31-40$ & 28 & 23.3 \\
\hline $41-50$ & 11 & 9.2 \\
\hline $51-60$ & 3 & 2.5 \\
\hline$>61$ & 1 & 0.8 \\
\hline Total & 120 & 100.0 \\
\hline \multicolumn{2}{|c|}{ Table 1: Age wise distribution of } \\
cases of alopecia areata
\end{tabular}

$\mathrm{x}^{2}=81.483, \mathrm{p}<0.0001$

\begin{tabular}{|c|c|c|}
\hline Gender & Frequency & \% of patients \\
\hline F & 40 & 33.3 \\
\hline M & 80 & 66.7 \\
\hline Total & 120 & 100.0 \\
\hline
\end{tabular}

Table 2: Table showing sex wise distribution of cases

$x^{2}=6.857 ; p<0.009$

\begin{tabular}{|c|c|c|}
\hline Religion & Frequency & \% of patients \\
\hline Hindu & 103 & 85.8 \\
\hline Muslim & 10 & 8.3 \\
\hline Christian & 7 & 5.8 \\
\hline others & - & - \\
\hline Total & 120 & 100.0 \\
\hline
\end{tabular}

Table 3: Table showing religion-wise distribution of cases

$¥$ Other religions considered were Sikh, Buddhism, Jainism, and Parsee $\mathrm{x}^{2}=68.925 ; \mathrm{p}<0.0001$ 


\section{ORIGINAL ARTICLE}

\begin{tabular}{|c|c|c|}
\hline Location & Frequency & \% of patients \\
\hline Rural & 33 & 27.5 \\
\hline Urban & 87 & 72.5 \\
\hline Total & 120 & 100.0 \\
\hline \multicolumn{2}{|c|}{ Table 4: Table Showing } \\
Location Wise Distribution of Cases \\
\hline
\end{tabular}

$\mathrm{x}^{2}=12.79 ; \mathrm{p}<0.0001$

\begin{tabular}{|c|c|c|}
\hline Income in Rs./- & Frequency & \% of patients \\
\hline$<3374$ & 23 & 19.2 \\
\hline $3375-6749$ & 42 & 35.0 \\
\hline $6750-13499$ & 39 & 32.5 \\
\hline$>13,500$ & 16 & 13.3 \\
\hline Total & 120 & 100.0 \\
\hline
\end{tabular}

Table 5: Table showing income wise distribution of cases

卬Based on Kuppuswamy socioeconomic status scale (Modified for 1998) $\mathrm{x}^{2}=8.359 ; \mathrm{p}<0.039$

\begin{tabular}{|l|c|c|}
\hline \multicolumn{1}{|c|}{ Educational status } & Frequency & \% of patients \\
\hline Illiterate & 14 & 11.7 \\
\hline literate & 24 & 20.0 \\
\hline Primary school & 11 & 9.2 \\
\hline High school & 10 & 8.3 \\
\hline P.U.C & 21 & 17.5 \\
\hline Degree/above & 40 & 33.3 \\
\hline \multicolumn{1}{|c|}{ Total } & 120 & 100.0 \\
\hline
\end{tabular}

Table 6: Table showing educational status wise distribution of cases

$\mathrm{x}^{2}=14.060 ; \mathrm{p}<.015$

The total number of illiterate population was $11.7 \%$.

\begin{tabular}{|l|c|c|}
\hline \multicolumn{1}{|c|}{ Occupation } & No of patients & \% of involvement \\
\hline Skilled & 37 & $30.83 \%$ \\
\hline Semiskilled & 32 & $26.6 \%$ \\
\hline Unskilled & 30 & $25.0 \%$ \\
\hline Not applicable & 21 & $17.5 \%$ \\
\hline
\end{tabular}

Table 7: Table showing occupation-wise distribution of cases

$\mathrm{x}^{2}=2.384 ; \mathrm{p}<0.497$

๙Based on Kuppuswamy socioeconomic status scale (Modified for 1998) 


\section{ORIGINAL ARTICLE}

\begin{tabular}{|c|c|c|c|c|}
\hline Area of involvement & No. of patients & \% of involvement & $\mathbf{x}^{\mathbf{2}}$ & $\mathbf{p}$ value \\
\hline Frontal & 23 & $19.17 \%$ & 25.214 & $<0.0001$ \\
\hline Parietal & 38 & $31.67 \%$ & 8.347 & $<0.004$ \\
\hline Occipital & 18 & $15.00 \%$ & 33.504 & $<0.0001$ \\
\hline Temporal & 14 & $11.67 \%$ & 41.342 & $<0.0001$ \\
\hline
\end{tabular}

Table 8: Table Showing Distribution of alopecia areata over scalp

\begin{tabular}{|c|c|c|c|c|}
\hline Area of face & No. of patients & \% of involvement & $\mathbf{x}^{\mathbf{2}}$ & $\mathbf{p}$ value \\
\hline Beard & 15 & $12.50 \%$ & 39.273 & $<0.0001$ \\
\hline Eyebrows & 9 & $7.50 \%$ & 52.906 & $<0.0001$ \\
\hline Eyelashes & 1 & $0.83 \%$ & 76.513 & $<0.0001$ \\
\hline Moustache & 9 & $7.50 \%$ & 52.906 & $<0.0001$ \\
\hline
\end{tabular}

Table 9: Table depicting distribution of alopecia areata over face

\begin{tabular}{|l|c|c|}
\hline \multicolumn{1}{|c|}{ Dermatological Diseases } & No. of Patients & Percentage \\
\hline Chronic urticaria & 1 & 0.8 \\
\hline Impetigo & 2 & 1.6 \\
\hline Lichen nitidus & 1 & 0.8 \\
\hline Vitiligo + Psoriasis & 1 & 0.8 \\
\hline Lichen planus & 1 & 0.8 \\
\hline LP Hypertrophicus & 1 & 0.8 \\
\hline Lichen planus pigmentosus & 1 & 0.8 \\
\hline PPKD & 1 & 0.8 \\
\hline Psoriasis & 1 & 0.8 \\
\hline Schambergs purpura & 1 & 0.8 \\
\hline Seborrhoeic dermatitis & 7 & 5.8 \\
\hline Steatocystoma Multiplex & 1 & 0.8 \\
\hline Lip tip Vitiligo+syringoma & 1 & 0.8 \\
\hline Nil & 100 & 83.3 \\
\hline \multicolumn{1}{|c|}{ Total } & 120 & 100 \\
\hline
\end{tabular}

Table 10: Table depicting association of dermatological disorders with cases

\begin{tabular}{|l|c|c|}
\hline \multicolumn{1}{|c|}{ Systemic Disorders } & Frequency & \% of patients \\
\hline Diabetes mellitus & 7 & 5.8 \\
\hline Bronchial Asthma & 5 & 4.2 \\
\hline Anemia & 5 & 4.2 \\
\hline Hypothyroidism & 3 & 2.5 \\
\hline Chronic Pyelonephritis & 1 & 0.8 \\
\hline
\end{tabular}




\section{ORIGINAL ARTICLE}

\begin{tabular}{|l|c|c|}
\hline Pneumonia & 1 & 0.8 \\
\hline Downs syndrome & 1 & 0.8 \\
\hline Varicose veins & 1 & 0.8 \\
\hline \multicolumn{1}{|c|}{ Total } & 120 & 100 \\
\hline
\end{tabular}

Table 11: Table depicting association of systemic disorders with cases

$\mathrm{x}^{2}=10.636 ; \mathrm{p}<0.155(\mathrm{NS})$

\begin{tabular}{|l|c|c|}
\hline Associated Disorders & Frequency & \% of patients \\
\hline Alopecia areata & 8 & 6.7 \\
\hline Bronchial Asthma & 3 & 2.5 \\
\hline Diabetes & 4 & 3.3 \\
\hline DM+HTN & 1 & .8 \\
\hline Psoriasis & 1 & .8 \\
\hline Vitiligo & 2 & 1.7 \\
\hline \multicolumn{1}{|c|}{ Total } & 120 & 100.0 \\
\hline
\end{tabular}

Table 12: Table depicting association of family history

of dermatological and systemic disorders with cases

$\mathrm{x}^{2}=5.730 ; \mathrm{p}<0.454$

\begin{tabular}{|l|c|c|}
\hline \multicolumn{1}{|c|}{ Nail changes } & Frequency & \% of patients \\
\hline Pitting & 14 & 11.7 \\
\hline Leukonychia & 7 & 5.8 \\
\hline 20 nail dystrophy & 1 & .8 \\
\hline Nil & 98 & 81.7 \\
\hline \hline
\end{tabular}

Table 13: Table showing various nail changes associated with cases

$\mathrm{x}^{2}=9.839 ; \mathrm{p}<0.009$

\begin{tabular}{|c|c|c|c|c|}
\hline \multicolumn{2}{|c|}{ Stress } & \multicolumn{2}{c|}{ LOCATE } & \multirow{2}{*}{ Total } \\
\cline { 3 - 4 } & & Rural & Urban & \\
\hline \multirow{2}{*}{ Absent (-ve) } & Frequency & 30 & 46 & 76 \\
\cline { 2 - 5 } & $\%$ & $39.5 \%$ & $60.5 \%$ & $100.0 \%$ \\
\hline \multirow{2}{*}{ Positive (+ve) } & Frequency & 3 & 41 & 44 \\
\cline { 2 - 5 } & $\%$ & $6.8 \%$ & $93.2 \%$ & $100.0 \%$ \\
\hline \multirow{2}{*}{ Total } & Frequency & 33 & 87 & 120 \\
\cline { 2 - 4 } & $\%$ & $27.5 \%$ & $72.5 \%$ & $100.0 \%$ \\
\hline
\end{tabular}

Table 14: Showing association of stress with cases in rural and urban areas

$\mathrm{CC}=.332 ; \mathrm{p}<0.0001$ 


\section{ORIGINAL ARTICLE}

\begin{tabular}{|c|c|c|c|c|}
\hline \multicolumn{2}{|c|}{ Income Group } & \multicolumn{2}{|c|}{ Stress } & \multirow{2}{*}{ Total } \\
\cline { 3 - 4 } & & Absent (-ve) & Positive (+ve) & \\
\hline \multirow{2}{*}{$<3374$} & Frequency & 22 & 1 & 23 \\
\cline { 2 - 5 } & $\%$ & $95.7 \%$ & $4.3 \%$ & $100.0 \%$ \\
\hline \multirow{2}{*}{$>13,500$} & Frequency & 0 & 16 & 16 \\
\cline { 2 - 5 } & $\%$ & $.0 \%$ & $100.0 \%$ & $100.0 \%$ \\
\hline \multirow{2}{*}{$3375-6749$} & Frequency & 40 & 2 & 42 \\
\cline { 2 - 5 } & $\%$ & $95.2 \%$ & $4.8 \%$ & $100.0 \%$ \\
\hline \multirow{2}{*}{$6750-13,499$} & Frequency & 14 & 25 & 39 \\
\cline { 2 - 5 } & $\%$ & $35.9 \%$ & $64.1 \%$ & $100.0 \%$ \\
\hline \multirow{2}{*}{ Total } & Frequency & 76 & 44 & 120 \\
\cline { 2 - 5 } & $\%$ & $63.3 \%$ & $36.7 \%$ & $100.0 \%$ \\
\hline
\end{tabular}

Table 15: Showing Association of Stress with Cases in Various Income Groups

\begin{tabular}{|c|c|c|}
\hline Area of involvement of scalp & $\begin{array}{c}\text { Present study } \\
\text { (\% of involvement) }\end{array}$ & $\begin{array}{l}\text { Awachat AK et al } 20 \\
\text { (\% of involvement) }\end{array}$ \\
\hline Parietal area & $31.67 \%(\mathrm{p}=0.004)$ & $52.45 \%$ \\
\hline Occipital area & $15.00 \%$ & $35.7 \%$ \\
\hline Temporal area & $11.67 \%$ & $33.3 \%$ \\
\hline Frontal area & $19.17 \%$ & $33 \%$ \\
\hline
\end{tabular}

Table 16: Table showing scalp involvement in alopecia areata

\begin{tabular}{|c|c|c|}
\hline Area of involvement & $\begin{array}{c}\text { Present study } \\
\text { (\% of involvement) }\end{array}$ & $\begin{array}{c}\text { Awachat AK et al20 } \\
\text { (\% of involvement) }\end{array}$ \\
\hline Beard area & $12.5 \%(\mathrm{p}=0.0001)$ & $12 \%$ \\
\hline
\end{tabular}

Table 17: Table showing beard involvement in alopecia areata

\section{Histopathology figures:}

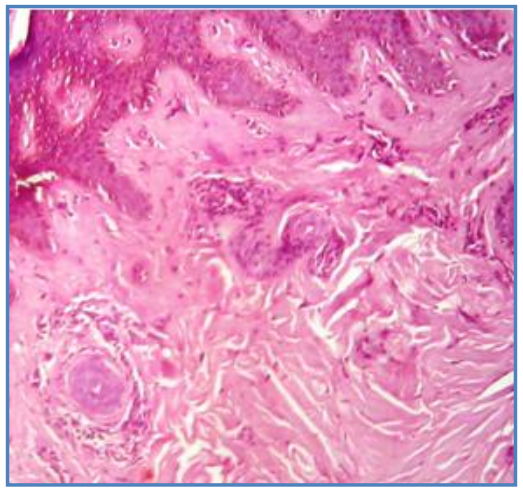

Fig. 1: Dermis shows hair follicles surrounded by inflammatory infiltrate.

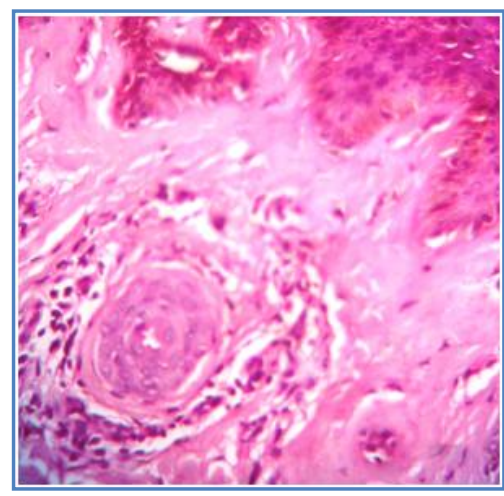

Fig. 2: Close-up view of lymphoid follicle surrounded by inflammatory infiltrate. 


\section{ORIGINAL ARTICLE}

\section{AUTHORS:}

1. Gopal M.G.

2. Praveen Kumar S.

3. Sharath Kumar B.C.

4. Ramesh M.

\section{PARTICULARS OF CONTRIBUTORS:}

1. Professor \& HOD, Department of Dermatology, Kempegowda Institute of Medical Sciences, Bangalore.

2. Assistant Professor, Department of Dermatology, M.S. Ramaiah Medical College and Teaching Hospitals, Bangalore.

3. Professor, Department of Dermatology, Kempegowda Institute of Medical Sciences, Bangalore.
4. Associate Professor, Department of Dermatology, Kempegowda Institute of Medical Sciences, Bangalore.

\section{NAME ADRRESS EMAIL ID OF THE} CORRESPONDING AUTHOR:

Dr. Praveen Kumar S.

Sai Krupa, 1547, 26 $6^{\text {th }}$ Main, $26^{\text {th }}$ Cross, $2^{\text {nd }}$ Sector, HSR Layout, Bangalore - 560034 . Email -drpraveen.1982@gmail.com

Date of Submission: 14/11/2013. Date of Peer Review: 15/11/2013. Date of Acceptance: 20/11/2013. Date of Publishing: 26/11/2013 